\title{
UMA ANÁLISE PLURIMODAL DO CONHECIMENTO A PARTIR DO PENSAMENTO DE- LEUZIANO: UMA EXPERIÊNCIA FILOSÓFICA NO ENSINO MÉDIO
}

\author{
Alessandro Rodrigues Pimenta* \\ Edinho Benésio Santos ${ }^{* *}$
}

\begin{abstract}
Resumo: O presente artigo analisa possibilidades do fazer filosófico no Ensino Médio, problematizando as experiências singulares dos indivíduos e fugindo de certezas definitivas no âmbito da filosofia. O artigo apresenta uma filosofia não mais como um desvelamento do ser, e sim, o modo pelo qual se explora os potenciais do sujeito na relação com o real, em vista de construir algo novo a partir das questões concretas de cada indivíduo. O que importa é, pois, o lugar de fala, uma geofilosofia, na qual estão presentes as crenças dos indivíduos, sua ideologia política, arte, religião etc. Para pensar esse fluxo de experiências, a figura do docente e discente são imprescindíveis, pois ambos são partícipes de um processo que possibilita a passagem das experiências pré-filosóficas para um saber consistente. Além disso, a preocupação é fazer uma análise aguçada de fenômenos que permitem vários olhares para uma mesma realidade, ou seja, é importante sempre perceber as zonas de fuga, pensando rizomaticamente a fim de que o conhecimento não permaneça estagnado.
\end{abstract}

Palavras-chave: Ensino. Desterritorialização; Filosofia Plurimodal; Rizoma; Território.

Resumen: El presente artículo analiza posibilidades del hacer filosófico en la Enseñanza Media, problematizando las experiencias singulares de los individuos y huyendo de certezas definitivas en el ámbito de la filosofía. El artículo presenta una filosofía no como un desvelamiento del ser, y si, como el modo por el cual se explora los potenciales del sujeto en la relación con lo real, con el propósito de construir algo nuevo desde las cuestiones concretas de cada individuo. Lo que importa es, pues, el lugar de habla, una geofilosofía, en la cual están presentes las creencias de los individuos, su ideología política, arte, religión, etc. Para pensar ese flujo de experiencias, las figuras del profesor y estudiante son imprescindibles, pues ambos participan de un proceso que posibilita el pasaje de las experiencias pre-filosóficas para un saber consistente. Además, el objetivo es hacer un análisis detallado de fenómenos que permitan varias miradas para una misma realidad, o sea, es importante siempre percibir las líneas de fuga, pensando rizomáticamente para que el conocimiento no permanezca estancado.

Palabras claves: Enseñanza; Desterritorialización; Filosofía Multimodal; Rizoma; Territorio.

\section{Introdução}

Em tempos de crise como autoritarismos e pandemia, os professores devem analisar todas as experiências possíveis $e$

\footnotetext{
* Pós-Doutorado em Filosofia pela UFRJ, sob supervisão do Prof. Dr. Filipe Ceppas, com cooperação acadêmica na Universidade de Évora. Doutor em Filosofia pela UGF. Coordenador do PROF FILO, Núcleo da UFT. Coordenador do GT Filosofar e Ensinar a Filosofar (2018-2020).

** Mestre em Filosofia pelo PROF FILO, Núcleo da UFT. Professor no IFTO.
}

dialogar com os estudantes no processo de ensino/aprendizagem de filosofia, a fim de que esse acontecimento ${ }^{3}$ não passe por es-

\footnotetext{
${ }^{3} \mathrm{O}$ acontecimento se passa no tempo, na realidade imanente. $\mathrm{O}$ acontecimento é puro devir, sem significação enquanto entidade plena. $\mathrm{O}$ acontecimento não se dá de uma vez por todas. Por isso que Zourabichvili diz claramente: "assim, o acontecimento (événement), sempre plural e precedido por outros, não têm, diferentemente dos pensamentos de proveniência fenomenológica, o caráter de um advento (avènement)" (ZOURABICHVILI, 2016, p. 33). Na
}

PIMENTA, Alessandro Rodrigues; SANTOS, Edinho Benésio. Uma análise plurimodal do conhecimento a partir do pensamento deleuziano: uma experiência filosófica no ensino médio. Revista SulAmericana de Filosofia e Educação. Número 34: nov. 2020 - abril 2021, p. 59-70. DOI: https://doi.org/10.26512/resafe.v2i34.35132 
quecido no tempo. Isso mostra que problemas filosóficos não estão dissociados da vida ou da experiência de cada indivíduo. Implica levar em consideração essas multiplicidades de vozes a partir das quais pode-se construir um pensamento filosófico em vista de refletir mais amplamente o Ensino de Filosofia no Ensino Médio. Trata-se de uma visão plurimodal pra pensar questões filosóficas. Não implica relativismo, uma vez que, qualquer conhecimento deve ter um lugar de fala, ou seja, a filosofia é pensada a partir de um território ${ }^{4}$; não um território único, pois cada sujeito tem experiências diferentes do mundo.

Uma nova forma de pensar a filosofia no Ensino Médio parece necessária diante de uma nova terra e um novo povo. Ao mesmo tempo em que Deleuze aponta para os gregos, alemães, franceses e ingleses como promotores de conceitos ${ }^{5}$, pode-se perceber nitidamente a abertura para fazer filosofia a partir de povos que ainda não têm um plano de imanência ${ }^{6}$ bem definido, pes-

verdade, o acontecimento se promove diante de encontros com a realidade que força o pensamento.

${ }^{4}$ Território, em Deleuze, não é um lugar do ponto de vista geográfico, algo estático, que está aí, mas uma condição de pensar o conhecimento em constante fluxo. É o lugar de fala do sujeito.

${ }^{5}$ Os conceitos não podem ser entendidos como fórmulas abstratas ou representativas das coisas, nem tampouco assume um caráter dogmático, sendo inflexível. Como diz o próprio Deleuze (2010, p. 29): "o conceito diz um acontecimento, não a essência ou a coisa". A própria ideia da criação acaba por atestar uma crise na subjetividade, pois não se trata de uma decisão arbitrária o ato da criação, mas do lançar-se do sujeito para fora de si. Uma das grandes novidades no pensamento de Deleuze é conceber a filosofia como criação.

${ }^{6}$ O plano de imanência é o horizonte onde se percebe todos os acontecimentos. "Os conceitos são como as vagas múltiplas que se erguem e que se abaixam, mas o plano de imanência é a vaga única que os soas que ainda sofrem com o peso da colonização até os dias atuais. Por esta razão, é fundamental partir da realidade dos alunos (as) para elaborar uma filosofia do futuro, abrindo espaço para autonomia dos estudantes, daqueles que estão nesse processo de construção do saber. A filosofia do futuro não pode ficar presa a uma forma exclusiva de pensar o conhecimento, ela é dinâmica, fluída, sempre se desterritorializando ${ }^{7}$, criando zonas de fuga, cruzando linhas.

Os conceitos empregados de Gilles Deleuze rompem com o fazer filosófico que busca uma verdade objetiva. Como os conceitos são infinitos, o conhecimento pode ser sempre atualizado, sendo enriquecido por novos elementos que possam aparecer. Aberto a novos fluxos e composições, o conhecimento fica à espreita do que pode acontecer. Com efeito, no tempo não há conceitos para serem descobertos, mas construídos.

\section{Da verdade do ser ao lugar vazio: por uma perspectiva filosófica deleuziana aplicada ao Ensino Médio}

O espaço da sala de aula tem sido visto, quase sempre, como o lugar no qual se encontram respostas para os problemas no âmbito do conhecimento. Alguns alunos (as) no Ensino Médio reclamam por objetividade

enrola e desenrola" (DELEUZE; GUATTARI, 2010, p. 45). Como condição para o pensamento, o plano de imanência ainda não é filosofia. O plano de imanência funciona como uma forma pela qual o conhecimento pode ser pensado, sendo correlativo ao conceito.

7 A desterritorialiazação não é uma "fuga" do real, mas uma forma de pensar a própria construção do território. Esse sair do território é a possibilidade de olhar as coisas lá fora e reterritorializar-se com novas formas de agenciamentos. 
na maneira de transmitir o conhecimento pelo professor, esperando que o docente possa dizer com clareza o que é a verdade e qual o método eficaz para encontrá-la. O desejo de uma verdade imutável mostra o quanto o pensamento científico positivista influencia os estudantes ainda no Ensino Médio, quando se busca uma ordem para o caos. Como na filosofia essa ordem nunca acontece, os alunos (as) tendem a reclamar o porquê de estudar filosofia.

Dessa inquietação dos alunos (as) no Ensino Médio já é possível filosofar, pois mostra, no fundo, o acontecimento de uma verdade que precisa ser problematizada. É preciso entender que os acontecimentos são experiências sempre novas, que acopladas num plano de imanência formam o tecido do conhecimento filosófico. Neste sentido, o sujeito não pode ficar preso aos conceitos existentes, tomando-os como verdades, mas criar "novos mundos", novas possibilidades de existência.

A perspectiva abordada traz consigo uma preocupação com o modo pelo qual a experiência pode ser problematizada e não mais como uma verdade dada como posse. A filosofia não é universal, não pode ser contada somente de um ponto de vista: "Uma disciplina que se desse por missão seguir um movimento criador vindo de outro lugar a abandonaria todo papel criador" (DELEUZE, 2013, p. 161). Deleuze apresenta um movimento dentro da filosofia, considerando as mais diversas formas de pensamento, mas nunca o total apego a uma verdade dita por outrem. Isso é a morte do pensamento, pois "o importante nunca foi acompanhar o movimento do vizinho, mas fazer seu próprio movimento" (Id., Ibid.). Qualquer tentativa de um desenvolvimento interno com tendência à generalização para pensar a verdade pela história pode ser questionada. É preciso interrogar o saber que estar aí. Não existe um conhecimento que não precisa ser aprimorado.

À luz do pensamento de Deleuze, o grande problema da escola é que ela põe fim ao movimento, ela consiste muito mais em um acerto de contas, uma espécie de tribunal que julga a capacidade dos alunos e, ao mesmo tempo, aponta o objeto como verdade para o pensamento. Destarte, a escola não é o lugar da verdade, mas um espaço de aprendizagem onde se descobre que os conceitos são inacabados. Por isso, a abertura que se deve ter com os alunos para retrabalharem sempre novos modos de ser do real, em vista de produzir o novo, de incrementar elementos que podem aprimorar os conceitos existentes. Como lugar do conhecimento, a escola tem como tarefa apresentar novas ideias para que os alunos possam se desenvolver enquanto estudante e cidadão, ampliando desse modo, sua visão de mundo. A verdade não se estabelece a priori, mas no tempo e contexto, sendo a experiência o lugar do encontro com as singularidades.

Não se pode confundir singularidade com individualidade, isso pode desembocar num subjetivismo, como acontecera com a filosofia cartesiana. Deleuze busca se livrar tanto da ideia de subjetividade como de objetividade, de modo a articular o conhecimento por um viés impessoal: "A vida do indivíduo dá lugar a uma vida impessoal $e$ no entanto singular, que produz um puro acontecimento liberado dos acidentes da vida interior e exterior, isto é, da subjetividade e da objetividade do que acontece" (AL- 
LIEZ, 2000, p. 21). Se a filosofia se processa por um viés singular, o termo reprodução tende a desaparecer no processo do ensino/aprendizagem. A filosofia deixa de ser pensada como doutrina ou espaço demarcado para a efetivação de um saber. O que se busca é uma certa autonomia do pensamento. Deleuze contribui com essa ideia na medida em que possibilita uma diluição do princípio de identidade, pois a verdade não possui mais um caráter indubitável ou um fundamento transcendente.

A barreira objetiva impede de pensar a filosofia como processo. Somente no vazio encontra-se possibilidade de ser. $\mathrm{O}$ preenchido se basta. $\mathrm{O}$ conhecimento como construção não é próprio de uma filosofia que preza pelo mundo estruturado, organizado, instituído. A preocupação no Ensino de Filosofia no Ensino Médio é de desenvolver uma nova forma de fazer filosofia que não se identifique simplesmente como uma educação instituída pelo Estado, na qual os alunos aprendem que as leituras sobre os autores da filosofia são fundamentais, mas não constituem verdades definitivas. Essa proposta apoiada em Deleuze alarga a compreensão da filosofia como um lugar que favorece o agenciamento ${ }^{8}$ de vários conceitos.

A fabricação de modelos para o ensino, impede, muitas vezes, de pensar as singularidades. Deixar os indivíduos falarem é sinal de reconhecimento, é não abortar suas experiências ao contribuírem para novas formas de saber. A filosofia pode ser vivenciada de forma pluridimodal, plurisubje-

${ }^{8} \mathrm{O}$ agenciamento é o modo como se articula questões na realidade em vista da construção de um saber. tiva e não harmônica. A tarefa do professor, neste sentido, seria criar condições de possibilidades para o pensar. Não existe o padrão para o pensar, mas modos de pensar (no plural). Essas formas de pensar devem ser analisadas com cautela, pois os alunos estão em contextos bem diferentes, e muitas vezes, querem respostas para situações atuais e que eles mesmos estão vivendo. Os conceitos surgidos na filosofia antiga precisam ser ressignificados.

A tentativa de estabelecer uma verdade enquanto imutável no Ocidente começa com Parmênides, sendo melhor sistematizada com a filosofia socrático-platônica $e$ aristotélica, na qual a razão passa a ser o critério para atestar o que pode ou não ser descartável como conhecimento legítimo, visto que a "tradição filosófica do ocidente foi hegemonizada por uma tendência que teve grande repercussão inicial a partir de Parmênides e depois na filosofia platônicoaristotélica. Trata-se da afirmação da identidade e da classificação dos seres" (GONTIJO, 2008, p. 52).

Toda esta reflexão quer apontar para novas possibilidades nas quais os estudantes de filosofia possam assumir para si a tarefa de exploradores do conhecimento, de um novo saber filosófico no Ensino Médio, sendo a experiência o lugar do encontro com as singularidades, resultando, portanto, na construção ou ressignificação de conceitos. O conhecimento filosófico pode emergir a partir do momento em que os alunos passam a explorar a realidade, suas experiências dentro e fora da sala de aula (LARRAURI, 2009, p. 13).

É importante salientar que a reflexão dos alunos sobre temas diversos parte de 
encontros diferenciados, o que permite dizer que a sociedade não se apresenta harmonicamente. Essa ideia que já se encontra no pensamento de Espinosa serve muito bem para evidenciar a questão discutida. Para Espinosa, se por um lado, existem situações que impulsionam o indivíduo a criar, por outro lado, existem as adversidades que agem como correntezas que forçam os indivíduos a andarem mais lentamente ou mesmo que os impedem de executar o que desejam. Nesse sentido, Gontijo (2008, p. 113) afirma que "toda a existência é composta de encontros. Há bons encontros e maus encontros. Os encontros produzem misturas entre os corpos. Um encontro afeta os corpos envolvidos nele".

A experiência é o lugar do encontro com as singularidades. Não é o encontro com o idêntico, com a unidade. A singularidade só é perceptível na repetição. Singularidade é diferente de opinião, de um discurso que se fundamenta no senso comum. Isso está mais para a generalidade, para uma crença no ordinário.

O singular, efêmero e pleno como o instante, é, ao invés, irrepetível embora haja apenas instantes presentes, não há dois instantes iguais. A repetição do mesmo, ou igual, a possibilidade de o mesmo dar-se outra vez, "esvaziaria" o singular daquilo mesmo que o singulariza: a impossibilidade de remissão, de analogia, de comparação, ponderação, comensuração, categorização. (MORAIS, 2008, p. 81, grifo do autor).

É próprio da filosofia que a verdade seja sempre vista como um acontecimento singular. Assim, novos arranjos carregam os conceitos que vão sendo forjados. Isso não é contraditório, pois o igual só se faz como reprodução. Dentro da filosofia, esse tipo de discurso limitaria a força do pensar e criar. $\mathrm{O}$ fazer filosófico é uma arte que exige sempre um novo olhar para a realidade, sendo cada intuição do real uma perspectiva singular.

O Ensino de Filosofia, na perspectiva que se apresenta neste artigo, não pode funcionar como um conjunto de mandamentos, como uma linguagem imposta pelo sistema de ensino. A linguagem funciona como um mecanismo pré-estabelecido nesse contexto, ou seja, como um instrumento apenas de recordação, pois à medida que se escreve, "sabe-se que uma língua é, na verdade, um sistema que está longe do equilíbrio, é um sistema em perpétuo desequilíbrio" (DELEUZE; PARNET, 1988, p. 84). Deleuze contrapõe um sistema ordenado com um modo criativo de fazer filosofia.

Uma filosofia que estabelece limites para o saber é um pensamento institucionalizado. Essa nova forma de fazer filosofia que não é filosofia, faz do "corpo"9 algo tão organizado que determina como sentar, vestir, comer, dentre outros. As instituições, nesse

\footnotetext{
9 A palavra "corpo" é associada a expressão "Corpo sem órgãos" ( $\mathrm{CsO}$ ) utilizada por Deleuze em muitas de suas obras. Corpo sem órgãos não é uma expressão oriunda do pensamento de Deleuze ou Guattari, foi inventada por Antony Arthur para contrapor o pronto, o organizado, o dado. O corpo sem órgãos é a casa da nossa potência. É preciso deixar claro que um corpo sem órgãos não é um corpo que se opõe a um corpo com órgão. Ele pode ser entendido como o modo pelo qual acontece a efetivação da potência. $\mathrm{O}$ que o sujeito precisa é mudar de corpo a todo momento. Trata-se de uma virtualidade e não de um corpo físico. Antony Arthur desenvolve essa ideia dentro do teatro.
} 
contexto, funcionam apenas como máquinas capazes de produzir "corpos".

Deleuze apresenta elementos que contribuem para subverter o conceito moderno de educação filosófica. Com base nisso, pode-se dizer que não existe bom senso ou senso comum que não deva ser percebido como um acontecimento, partindo de uma via investigativa: "O paradoxo é, em primeiro lugar, o que destrói o bom senso como sentido único, mas, em seguida, o que destrói o senso comum como designação de identidades fixas" (DELEUZE, 2015, p. 03). A preocupação, antes de tudo, não é determinar a verdade, mas promover problemas como condição para o fazer filosófico. Os problemas são articulados e não dados como fórmulas ou códigos fabricados. Não existe um método pré-existente para fazer filosofia. Dessa forma, segundo Deleuze, "a filosofia de algum modo, fundamenta-se como um tribunal da razão, do julgamento que disciplina e afirma um modo de pensar" (BRITO; RAMOS, 2014, p. 186).

Existe um grande problema quanto ao posicionamento da escola na formação filosófica dos estudantes. Como espaço de discussões - sua tarefa em alguns momentos tem sido fabricar aquilo que o homem deve ser. Até que ponto isso contribui para a formação dos indivíduos como sujeitos ativos no processo do conhecimento? Lipman (2001, p. 19) salienta que a "escola é um campo de batalha, pois é, mais que qualquer outra instituição social, aquela que fabrica a sociedade do futuro, e virtualmente todo grupo ou facção social aspira controlar a escola tendo em vista seus próprios objetivos". Nesse contexto, o professor é um agente ativo que deve, a partir das vivências dos alunos, promover provocações e problemas a eles. O pensamento de Deleuze abre horizontes para inúmeras possibilidades, o que permite dizer que o conhecimento aponta sempre para uma revolução que deve ser feita no âmbito filosófico, uma revolução que carece de muita resistência.

As circunstâncias estão sempre mudando, e é nesse dinamismo que a verdade é dita. Com efeito, a tarefa de uma educação filosófica deve levar em consideração os desafios gerais da sociedade, podendo incorporar tais problemas aos temas trabalhados em sala de aula, provocando uma discussão mais abrangente de filosofia no Ensino Médio.

A essência no conhecimento foi colocada em xeque em nome de um projeto filosófico que se desdobra pela lógica empírica transcendental. Na experiência, acontece o desenvolvimento do pensamento. Como os signos ${ }^{10}$ na experiência sempre perturbam o pensamento, a filosofia se torna um exercício constante. O mundo está sempre se atualizando por meio de novas imagens ${ }^{11}$ que o pensamento vai problematizan-

\footnotetext{
10 Signos são imagens a partir das quais o pensamento pode acontecer. A filosofia só acontece por imagens. Os signos são os elementos básicos que ajudam na confecção de uma teoria. Sem signos o conhecimento se torna vazio.

11 O conceito de imagem em Deleuze aparece com mais frequência em suas obras o que é Filosofia? Na obra Proust e os signos, Diferença e Repetição e Conversações. Nessas três últimas aparece a imagem enquanto imagem de pensamento, mas aparece também como imagem cinematográfica. Nas Conversações fica claro o conceito de imagem: "Existem imagens, as coisas mesmas não imagens, porque as imagens não estão na cabeça, no cérebro. Ao contrário, é o cérebro que é uma imagem entre outras" (DELEUZE, 2013, p. 59). As imagens são virtualidades que possibilitam pensar o mundo.
} 
do, tornando isso um novo acontecimento. Essa abertura faz da filosofia um saber desprovido de determinações, sejam elas sociais, econômicas, cientificas ou mesmo psicanalíticas.

É importante fugir de uma lógica que mostra a verdade como encontrada, desvelada e não como construção, podendo passar por transformações ao longo do tempo. Para tanto, os estudantes devem começar a colocar problemas com toda autonomia, a fim de que os conceitos de filosofia como um acontecimento singular possam desarticular um discurso que supera o idealismo e o objetivismo, o particular e o geral.

\section{Por uma filosofia rizomática: condições de desterritorialização $e$ reterritorialização no Ensino Médio}

No Ensino Médio, a ideia de rizoma consiste na possibilidade de filosofar sem partir de um ponto inicial determinante $e$ com pretensões de atingir uma ordem "perfeita" para a construção do conhecimento. Tudo pode mudar, mudar a rota, a profundidade, a complexidade de linhas, dentre outros fatores: "Não existem pontos ou posições num rizoma como se encontra numa estrutura, numa árvore, numa raiz. Existem somente linhas" (DELEUZE; GUATTARI, 2011, p.24). Qualquer código no processo do fazer filosófico limita o conhecimento, colocando barreiras nas linhas de fugas $e$ impossibilitando a difusão de novas ideias. Fazer rizoma no Ensino Médio é deixar fluir a potência de vida que cada aluno tem dentro de si; é criar condições para que o pensamento não pare no tempo; é perfurar vários terrenos sob uma ótica de criação; é martelar sobre assuntos, que embora sendo os mesmos, apresentam sentidos diferentes, buscando desse modo zonas de fuga; fazer rizoma é deslizar, é criar ou ressignificar conceitos a partir de acontecimentos que se promove por encontros; fazer rizoma é apossar do par conceito/problema tornando a filosofia uma disciplina singular; no rizoma há conexões, relações; fazer rizoma é aceitar o desafio de ser provocado e encarar isso como uma condição para perfurar novos terrenos. O conhecimento rizomático é inesgotável no sentido de permitir constantemente novas interpretações de descrições fenomênicas. O rizoma é um terreno aberto por onde podem passar várias linhas. Há espaços sempre abertos para o sujeito transitar e produzir saberes. No rizoma, não se pode pensar o conhecimento aprisionado por métodos.

Sempre é possivel pensar linhas de fugas no rizoma, mesmo dentro de um conhecimento estruturado. Por mais que um livro didático no Ensino Médio tenha uma estrutura lógica a ser seguida, diretrizes que orientam como trabalhá-lo, sempre será possível desterrritorializar-se. A experiência do pensar não determina limites, não se põe a priori o que deve ser pensado. É próprio do rizoma provocar ruptura, descontinuidade: "Faça a linha e nunca o ponto! A velocidade transforma o ponto em linha! Seja rápido, mesmo parado!" (DELEUZE; GUATTARI, 2011, p. 48). É preciso traçar sempre novas linhas de "fuga". O pensamento não pode ser estático, ele deve ganhar velocidade. $\mathrm{O}$ sujeito se move dentro de um mesmo contexto, ele pode pensar rizomaticamente sem sair de seu habitat natural. No pensamento filosófico rizomático, as questões sempre vão surgir. No rizoma, agrega-se uma multiplici- 
dade de elementos que compõe a realidade do conceito. Tudo é rizoma na filosofia de Deleuze, à medida em que pode ser perfurado em termos de conhecimento. O rizoma é como uma zona de disjunção inclusiva. Com feito, "qualquer ponto de um rizoma pode ser conectado a qualquer outro e deve sê-lo. É muito diferente da árvore ou raiz que fixam um ponto, uma ordem" (Ibid., p.22).

É importante nesse modo de fazer filosofia, valorizar as experiências de cada aluno (as singularidades), trazendo-as para a reflexão, de modo a fazer disso elementos constitutivos de conhecimento. É a partir disso que se pode pensar uma geofilosofia, a qual "pode ser entendida como uma busca da compreensão das destituições ou restituições que ocorrem no contexto desses elementos que a terra abriga" (SANTOS, 2011, p. 156). Uma geofilosofia não pode ser pensada a partir de argumentos que não condizem com a realidade. Cada lugar tem suas preocupações.

Nesta perspectiva, o professor vai ajudar os alunos, dialogando e oferecendolhes ferramentas para o pensar, provocandoos constantemente a ficarem atentos aos signos que também os desestabilizam através de um ato violento para o pensamento. Os alunos devem ter uma certa autonomia, sendo capazes de ter interesse pelo que estão desenvolvendo; deve contar com as contribuições dos professores para lapidar o que é capaz de atrapalhar o processo ensino/aprendizagem. $\mathrm{O}$ importante diante de tudo isso, é garantir um lugar de fala aos estudantes, é atentar para o território do qual eles fazem parte. Deleuze sempre deixa claro que a terra não pode ser confundida com o território, já que a "terra é esse ponto in- tenso no mais profundo do território, ou então projetado fora do território como ponto focal, e onde se reúnem todas as forças num corpo a corpo" (DELEUZE; GUATTARI, 2012, p. 162). Pode-se dizer que a terra, no geral, comporta vários territórios. Diante de uma nova terra, de um novo povo, num novo modo de produção em crise, a captura é por uma nova "ordem" do fazer filosófico.

A geografia aqui é do modo mesmo dos alunos na relação que têm com a aprendizagem, com o contexto no qual estão inseridos, suas crenças, sua ideologia política, sua religião, sua arte, dentre outros. Não se trata de uma geografia espacial, mas aquela que possibilita a arte do pensamento. A geografia nesse contexto vai além da terra, é um voo do pensamento em busca da criação de conceitos. O solo para o pensamento pode acontecer quando determinados estudantes de filosofia colocam questões atuais que merecem ser debatidas, levantando aí uma série de problemas. A intenção é que o aluno apareça, que ele se sinta partícipe direto na construção do conhecimento. Tal construção foge da velha lógica imposta da Europa para a América Latina como critério de verdade.

A composição de fluxos que formam o território não tem a pretensão de ser um símbolo de poder. As várias bifurcações feitas pelos alunos no Ensino Médio permitem alargar o conceito acerca de uma nova filosofia. Isso nada mais é do que o deslizamento, o pensamento se desterritorializando, levando em conta a condição plurimodal com que as coisas são concebidas em estado diferentes. Isso enriquece a filosofia.

O território aparece como um modo de pensar, é uma expressão do real. Essa maneira de expressar uma realidade parte de 
imagens que se constroem no território. Deleuze faz questão de dizer que não é o sujeito que determina o território. Cada morada tem seus traços próprios, suas linhas que caracterizam tal território e "essas qualidades são assinaturas, mas a assinatura, o nome próprio, não a marca constituída de um sujeito, é a marca constituinte de um domínio, de uma morada. A assinatura não é a indicação de uma pessoa, é a formação aleatória de um domínio" (DELEUZE; GUATTARI, 2012, p. 130).

Os conceitos são expressões criativas do pensamento a partir de um plano de imanência. A desterritorialiazação é a possibilidade de os indivíduos fugirem de um conhecimento arbitrário. A verdade não pode ser invariável. Pensar na desterritorialização é atestar um devir na história do pensamento: "A desterritorialização absoluta não existe sem reterritorialização. A filosofia se reterritorializa sobre o conceito. O conceito não é objeto, mas território. Não há objeto, mas um território" (DELEUZE; GUATTARI, 2010, p. 121-122).

Os alunos não abandonam o território quando saem de suas casas e vão para a escola. O que acontece é um processo de desterritorialização. As marcas do território eles carregam consigo, e, além disso, buscam uma nova forma de pensar, buscam conhecer novos territórios. Aqui é possível perceber que o conceito de desterritorialização não significa de modo algum se mover de um lugar para o outro, mas fazer mover o pensamento, pensar para além do dado, do estabelecido como verdade.

Os alunos traçam novos modos de ser, sem precisar sair de sua terra natal para buscar novas formas de pensar. É importan- te pensar a filosofia a partir da realidade local. Para Deleuze, "assim, Nietzsche fundou a geofilosofia, procurando determinar os caracteres nacionais da filosofia francesa, inglesa e alemã" (Ibid., p. 123). Os alemães, os franceses e inglês criaram e recriam conceitos. Mas a ideia básica aqui é fugir da esfera da comunicação para pensar a efetivação mesma do conhecimento: "Não nos falta comunicação, ao contrário, nós temos comunicação demais, falta-nos criação. Faltanos resistência ao presente" (Ibid., p. 130, grifo do autor). Essa expressão de Deleuze parece ir de encontro com a situação atual no Brasil e no mundo. São tantas informações, de modo a serem confundidas com o conhecimento propriamente posto como construção. No segundo momento da expressão, aponta-se para uma filosofia prática, para uma situação em que merece um posicionamento crítico quanto ao que está posto. É de uma visão crítica e atenta que novos conceitos podem surgir.

Sobre a desterritorialização, Pedro Gontijo coloca questões pontuais, estabelecendo uma nítida relação com o contexto escolar.

O que seria experimentar esta desterritorialização na escola? Podemos postular que, primeiramente, tal desterritorialização provoca um sentimento de estrangeirização, de estranhamento do lugar, da escola. Ficamos então a perguntar sobre o que se está fazendo ali. Aquele lugar do qual tantas vezes se entra e se sai, no qual tantas aulas foram dadas. Como essa rotina, esses gestos feitos tantas e tantas vezes em repetição podem agora serem estranhos? Como pode parecer um contrassenso quando vemos quase todos continu-

Número 34: nov. 2020 - abril 2021 
arem com a mesma rotina de sempre? (GONTIJO, 2008, p. 78).

Gontijo tenta problematizar o percurso angustiante de alguns anos para chegar até à escola todos os dias. Além disso, o aluno pode se sentir estrangeiro nos primeiros dias de aula quando não se criaram laços para poder se expressar, questionar acerca de algumas dúvidas que podem surgir. Quando essa adaptação custa a acontecer, os alunos tendem a se sentirem desconfortáveis no ambiente de estudo. $\mathrm{O}$ pior problema é quando o aluno vai à escola e se sente tão acomodado, acreditando que aquilo que pratica todos os dias, suas idas $e$ vindas da escola, já constitui o ser estudante, sem no entanto, se perguntar o porquê da sua vida ali, como se nada the causasse perplexidade. Esse modo de ser estudante não constitui uma desterritorialização $e$ reterritorialização estritamente falando. Ele pode sair de seu contexto, está em outro lugar, com outras pessoas, diante de novas ideias, mas sua vida permanece a mesma. A escola exige uma "nova pessoa" e quer que o ser humano seja sempre contemporâneo, atualizado com as questões do mundo. Não pede para abandonar seu território, mas pensar o novo, o diferente. É preciso ser resistente, pensar por devir ${ }^{12}$. Esse devir descarta a ideia de fim do território ou enfraquecimento dos mesmos. O que se busca é mostrar como é possível nessa filosofia do devir pensar as práticas humanas. Esse pensar é um modo de fazer agenciamento, confirmando uma filo-

\footnotetext{
${ }^{12}$ Devir em Deleuze não representa uma mera transformação sensível, mas um movimento que o pensamento faz visando uma novidade no conhecimento por meio da resistência.
}

sofia aberta. Como os conceitos são infinitos, vários componentes podem ser incrementados.

\section{Considerações finais}

O que se buscou, até então, é pensar a filosofia plurimodal como zonas de fuga, rompendo com um modo de pensar o conhecimento a partir de um processo linear constituído por etapas planejadas, encandeadas. Do início ao fim do artigo, buscou-se fugir de uma formação filosófica como uma montagem de quebra cabeça, com as peças predeterminadas; um conhecimento prédeterminado tem uma proposta curricular fechada, sem liberdade para desenvolver o pensamento.

Os pequenos momentos da vida suscitam acontecimentos, que fazem o pensamento repetir e criar o diferente, evitando ficar num discurso meramente abstrato. A filosofia deve ser pensada a partir da realidade concreta, por meio do enfrentamento do sujeito com sua própria terra. A filosofia se situa num espaço e tempo, tornando-se, assim, uma geofilosofia, na qual o solo permite o cruzamento das forças. E não se trata de permanecer no plano subjetivo para fazer filosofia, mas a partir de encontros que começam pela superfície, podendo os conceitos operar de maneira horizontal certas conexões. Essa geofilosofia é uma maneira singular de fazer filosofia que não está dissociada do contexto. A filosofia enquanto saber prático é algo fluído, que sempre se desterritorializa no seu caráter fugidio, que não se limita a quaisquer coordenadas, sejam elas simples ou complexas. É desse modo que a filosofia se expressa pela multiplicidade num plano de imanência 
Portanto, não se buscou pensar a filosofia, bem como sua aprendizagem ou exercício, inserida em um sistema unificado, ou mesmo como uma verdade dogmática, mas em traçar linhas de fuga, em vista de fazer uma filosofia rizomática. No rizoma podemse encontrar entradas diferentes para construir o conhecimento. Nele, várias linhas se conectam sem limitar ou determinar o conhecimento pelo pensamento. As multiplicidades aparecem trazendo sentidos diferentes para expressar o ser. A intuição para a efetivação da filosofia passa pelo território, sendo este não como um mero espaço físico, mas condição para o filosofar, como lugar de fala $e$, aqui, tendo a aprendizagem e o Ensino de Filosofia como privilegiados.

\section{Referências}

ALLIEZ, É. Gilles Deleuze: uma vida filosófica. São Paulo: Editora 34, 2000.

BRITO, M. R; RAMOS, M. Do pensamento dogmático ao pensamento problema: por uma aprendizagem - acontecimento. Comunicações, V, 21, n. 21. 2014. p. 183-198. Disponível em:

https://www.metodista.br/revistas/revistasunimep/index.php/comunicacoes/article/viewFile/1077/1330 >. Acesso em: 13/12/2018.

DELEUZE, G. Conversações. Trad. de Peter. P. P. São Paulo: Editora 34, 2013.

. Lógica do sentido. São Paulo, Perspectiva, 2015.

. Mil Platôs Vol. I: capitalismo e esquizofrenia 2. São Paulo: Editora 34, 2011.

. Mil Platôs Vol. IV: Capitalismo e esquizofrenia 2. São Paulo: Editora 34, 2012.

.; GUATTARI, F. O que é a Filosofia?. Rio de Janeiro: Editora 34, 2010.

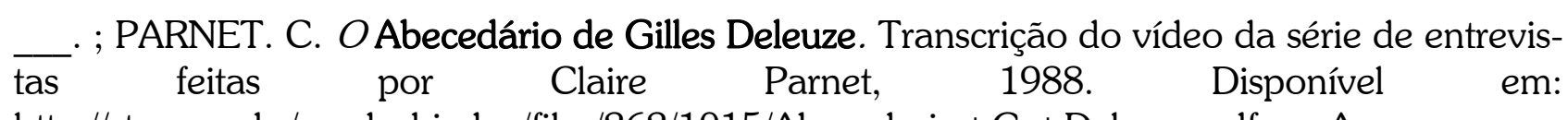
http://stoa.usp.br/prodsubjeduc/files/262/1015/Abecedario+G.+Deleuze.pdf. Acesso em: $12 / 11 / 2018$.

GONTIJO, P. E. Nos caminhos de uma educação por vir: ressonâncias e deslocamentos em Deleuze. Campinas/SP: Unicamp, 2008. Disponível em: http://www.repositorio.unicamp.br/bitstream/REPOSIP/251862/1/Gontijo_PedroErgnaldo_D.p df. Acesso em 20/05/2019.

LAPOUJADE, D. Deleuze, os movimentos aberrantes. São Paulo: N-1, 2015.

LARRAURI, M. O desejo segundo Gilles Deleuze. São Paulo: Ciranda Cultural, 2009.

LIPMAN. M. O pensar a educação. Petrópolis: Vozes, 2001. 
MORAIS, D. Singularidade e repetição: "eterno retorno" como símbolo da afirmatividade trágica. Universidade Estadual do Rio Grande do Norte. Revista Trilhas filosóficas, Ano $1 \cdot \mathrm{N}^{\mathrm{O}} 1$ • Jan/Jun 2008.

Disponível em: http://www.uern.br/outros/trilhasfilosoficas/conteudo/singularidade\%20e\%20repeticao_.pdf. Acesso em: 05/08/ 2018.

SANTOS, W. M. O conceito de geofilosofia em Deleuze e Guattari. Bahia: Universidade Estadual da Bahia. Revista Pandora Brasil, 34, 155-169, Setembro de 2011. Disponível em: https://docplayer.com.br/9378773-O-conceito-de-geofilosofia-em-deleuze-e-guattari.html. Acesso em: 12/01/2019.

SCHOPKE, R. Por uma filosofia da diferença: Gilles Deleuze, um pensador nômade. Rio de Janeiro: Contraponto, 2012.

ZOURABICHVILI, F. Deleuze: uma filosofia do acontecimento. São Paulo: Editora 34, 2016.

Recebido em: 30/05/2020 Aprovado em: 15/10/2020 